\title{
$\checkmark$ Research Square \\ Underweight Among the Children Under Five Years Age in Northeastern States, India
}

\author{
Kirti Chauhan ( $\nabla$ kirti070197@gmail.com ) \\ International Institute for Population Sciences

\section{Vekutulu Chiero} \\ International Institute for Population Sciences

\section{Debarghya Mandal} \\ International Institute for Population Sciences \\ Kh Jitenkumar Singh \\ National Institute of Medical Statistics
}

\section{Research Article}

Keywords: Underweight, Prevalence, Risk, Children, Under-5-years

Posted Date: January 31st, 2022

DOI: https://doi.org/10.21203/rs.3.rs-1310990/v1

License: (c) (1) This work is licensed under a Creative Commons Attribution 4.0 International License. Read Full License 


\section{Abstract}

\section{Background}

Age-appropriate weight or underweight is one of the normative indexes of physical development that describe the nutritional state of children. Northeast India has a wide range of sociocultural child-rearing activities due to the region's varied tribal and ethnic populations which in some or the other way affect the nutritional status among children in early ages. An attempt has been made to assess the prevalence and determine the risk of underweight among children in northeast region in India.

\section{Methods}

The present study is based on a publicly available National Family Health Survey (NFHS-4), 2015-16 data. Multilevel random intercept model approach has been used to investigate the impact of independent variables at different social hierarchical levels on the underweight status in the study population.

\section{Results}

Children whose mother's level of education was no education or primary were 1.13 and 1.34 times more likely to be underweight respectively than those with secondary or higher level of education. The risk of being underweight were 2.4 times higher among children of 4 years of age compared to those with age less than 1 year. Poorest wealth quintile had 2.45 times higher chance of being underweight.

\section{Conclusion}

Study suggests that education of mother's education, child's sex, age, type of residence, social status, and household's wealth index affect the underweight among children. Hence, to combat the situation in northeast states, policymakers must make policies with a strong reliance on communities with a higher prevalence and risk.

\section{Introduction}

Malnutrition is best described as shortages, excesses, or imbalances in a person's energy and nutrient intake (WHO, 2020). Stunting (age-appropriate height), wasting (age-appropriate height), underweight (age-appropriate weight), and micronutrient scarcity or insufficiencies are all examples of undernutrition or nutritional deficiencies. Obesity, which is described as an individual's micronutrient levels being excessive, is the other condition. Anthropometric and biomarker measurements are used to assess nutritional status. Weight-for-height (wasting), height-for-age (stunting), and age-appropriate weight (underweight) are the three normative indexes of physical development that describe the nutritional state of children in practice. 
Underweight is a cumulative index of stunting and wasting, which means that infants will be underweight whether they are stunted, wasted, or both, and whether their $z$ score is less than two standard deviations (Belitz et. al, 2010). All of these three indexes can be classified as severe, moderate, and mild levels determined by cut-off points defined by the World Health Organization in the form of z-scores.

Childhood malnutrition has been one of the main public health problems in low and middle-income countries in recent decades (Wang et. al., 2009). According to UNICEF estimates, almost 101 million children worldwide are underweight. Further, from the estimates from United Nations (UN), about 6.3 million under-five mortalities occurred in India, of which $45 \%$ died due to undernutrition, which includes three indices namely stunting, wasting, and underweight (UNICEF levels and trends in child mortality report 2020). Besides, according to UNICEF, malnutrition is responsible for approximately 69 percent of deaths among children under the age of five in India.

India is the world's second-most populous country, with 121 billion people, and children accounting for $39 \%$ of the total population. The figures show that children aged 0 to 5 years account for most of the population with $29 \%$ of the total. India had a $35.7 \%$ prevalence of underweight among children of age below five (NFHS-4 Report, 2015-16). India has therefore listed in the countries where malnutrition and child mortality is alarmingly high.

Malnutrition affects people majorly in the same age group in every country. According to WHO India includes the highest proportion of children who are underweight, i.e. $43 \%$ among developing countries. Poverty, hunger, and illness are all related to a child's nutritional status, which is a major indicator of poverty in a community (Rabbi and Karmaker, 2015). The Northeast region comprises of eight small states: Arunachal Pradesh, Assam, Manipur, Meghalaya, Mizoram, Nagaland, Sikkim, and Tripura. Northeast India is not only geographically separated from the rest of the country due to rugged terrain and inadequate infrastructure, but it also has a wide range of sociocultural child-rearing activities due to the region's varied tribal and ethnic populations. The shortage of basic infrastructure is directly or indirectly responsible for the high prevalence of child morbidity and malnutrition in this area. This indigenous people have no simple facilities in conventional roofing huts (Dinachandra, et al., 2015). Besides, the household atmosphere in which a child is born and raised is a significant determinant of child health, especially in the remote and inaccessible areas of northeast India (Dinachandra, et al., 2015). Physical and social causes, behavioural factors, health-care service-related factors, and biological factors are all examples of environmental factors which in some or the other way affect the nutritional status among children (Bhutia, 2014). Socio-cultural influences play an important part in shaping the caregiver's attitude toward feeding and caring activities. The condition is made worse by faulty eating practises, which are compounded by the mother's low nutritional status (Bhutia, 2014).

According to data published by the Department of the Registrar General of India, although the mortality rate, particularly for infants and children under the age of five, has been declining over time, there are still some states where these rates are high. This shows that instead of the growth in the healthcare sector 
and economy in India, the young population particularly in the age group 0-5 years continuously lost their lives due to inadequate nutrition and proper medical intervention.

\section{Need Of The Study}

The child's mortality rates and nutritional status represent threats to his or her health, especially underweight. Despite numerous interventions and initiatives aimed at minimizing malnutrition and mortality among children, the situation remains a major concern that requires immediate attention. Northeast India is not only physically isolated from the rest of the world due to harsh geography and poor infrastructure, but it also has a diverse spectrum of sociocultural child-rearing practices due to the area's diverse tribal and ethnic communities, which influences the prevalence of underweight status in the region directly or indirectly. Moreover, studies have shown that some part of northeast states has certain level of food insecurity insecurities (Chyne et. al., 2017; Roy et. al., 2015). According to a paper published by India State-Level Disease Burden Initiative, Child Development Failure (GCF) is responsible for over one-fifth of all under- 5 deaths and disease burden in India, with the prevalence of GCF measures ranging from 16.5 to 42.2 percent for underweight in 2017. Hence, it is important to study various aspects of underweight status of the child younger than five years old explicitly in northeast states of India.

\section{Objectives}

The main objectives of this study are as follows:

1. To examine the prevalence of underweight among children younger than the age of five years in northeast states, India.

2. To identify the determinants of underweight among children younger than the age of five years in northeast states, India.

3. To examine the risk difference of underweight among poor and non-poor household of children under five years of age in northeastern states, India.

\section{Data And Methods}

\section{Data}

The present study is based on a publicly available National Family Health Survey (NFHS-4), 2015-16 data. NFHS-4 is the fourth volume in the NFHS series includes data for each of the States and Union Territories on India's population, health, and nutrition. NFHS-4 was conducted under the supervision of the Minister of Health and Family Welfare, synchronized with the International Institute for Population Sciences, Mumbai. The survey covered a range of health-related issues including child health, maternal health, fertility, malaria, reproductive health, infant and child mortality, non-communicable diseases, and HIV knowledge and perception. Only 8 states have been extracted from the nationwide survey data. The study includes 32,005 children (boys $=16,300$ and girls $=15,705$ ) under the age of five years from the 
northeast region which includes the above eight states. To assess the underweight of individuals or populations, anthropometry is widely recognized as one of the useful techniques since, it is highly sensitive to detect undernutrition. The association of underweight among children below five years of age with non-food determinants has been studied.

\section{Outcome variables}

For studying the prevalence of underweight using the WHO references for Northeast Asia the index has been classified into two categories present and not present i.e., recoded as 'yes' if the standard deviation is less than -200 (as the values of the variables were given as standard deviation and were not converted into z-scores) and 'no' for the rest of the values.

\section{Explanatory variables}

Various demographic, socio-economic, and health characteristics considered to be associated with the status of being underweight were taken as explanatory variables. More precisely, maternal factors like mother's age, her education level, working status in the last 12 months before the survey, duration of breastfeeding. Children's factors such as the age (in months), sex of the child, birth order, size of the child (small, average, large) has been included in the analysis. The wealth index, number of household members, type of toilet facility, source of drinking water, safe cooking fuel, place of residence, social status, and the household's wealth index were all regarded as explanatory variables in the analysis.

\section{Methods}

Statistical analysis includes chi-square which is a nonparametric test that has been used to analyze the relationship between the underweight status and all the independent variables. Binary logistic regression has been used to analyze the underweight status after adjusting for the latter explanatory variables. A multilevel random intercept model has also been used which enables to analyze of the effect of independent variables at various social hierarchical levels on the underweight status of children below five years of age in northeastern states. Finally, an adjusted risk difference has been computed to express the relationship between two predicted probabilities based on the estimated model and a set of observations.

\section{Results And Discussion}

Table 1 depicts the percent distribution of children under five years of age along with underweight prevalence, crude, and adjusted odds ratio by background characteristics of the child and the mother in Northeast states, India.

The mothers in the age group of 25-34 years had the most infants, followed by those in the age group of 15-24 years. 61.2 percent of mothers have a secondary or higher level of education. As shown in the table 80 percent of the children were having an average size or more than average. A birth order of one is seen in 68.9 percent of the children. 71.1 percent of children were also receiving breast milk at the time of the 
study. About 85 percent of the 32,005 children in the survey lived in rural regions. Hindu children accounted for $46.9 \%$ of all children, the highest percentage, led by Muslims (32.1\%), Christians (18.1\%), and children of other religions (2.9\%). Males accounted for nearly 89 percent of household heads. 56 percent of the households had 5 to 8 members. 25.3 percent of the children in the study come from the poorest families, 21.2 percent from the poorer family, 19.8 percent from the middle-income family, 19.8 percent from the middle-income community, 18.7 percent from the wealthier family, and the remaining children come from the richest family. Table 1 shows that the Schedule tribe has the highest percentage of children (28.7\%), led by OBC (18.6\%), Schedule caste (8.6\%), and Others (8.6\%). (44.0\%). In addition, 38.7percent of households said they don't have upgraded toilet facilities, 73.3 percent said they don't have clean drinking water, and 21.2 percent reported that they don't use safe cooking fuel.

Column 2 shows the prevalence of underweight. The prevalence of underweight has increased with an increase in the age group of the mother, i.e., from 15-24 years to 35-49 years. The prevalence of underweight in children has declined dramatically when the mother's educational degree grows, from uneducated mothers $(41.1 \%)$ to those of at least secondary schooling $(21.2 \%)$, which is still substantial. The chi square value is considerably high $(1.93 .30, p=0.001)$, suggesting a high relationship between the mother's level of schooling and status of underweight among children. Children with small size at the time of birth have shown more prevalence of underweight (34.8\%) than those with the average or above $(25.5 \%)$ the size at birth. The chi square value is again very high $(228.42, p=0.001)$ hence, a very strong association between the size of child at the time of birth and the underweight can be seen. Male child has shown more prevalence of underweight than female child. As the age of child increases the prevalence of underweight increases significantly from 18.2 percent to 31.7 percent. Chi square value $(328.10, p=0.001)$ shows a very high association between the age and underweight prevalence up-to age five. Children with birth order one and birth interval one have a higher prevalence of underweight (36.5\%), whereas those with a birth order of less than two have the lowest prevalence (24.7\%). As a consequence, there is a strong positive association between birth order and underweight ( $\mathbb{\nabla}^{2}$ value $\left.288.50, p=0.001\right)$. Those children who were never breastfed show a higher prevalence of underweight than those who stopped or are still breastfeeding. The table also indicates that children living in rural areas have a higher prevalence $(28.9 \%)$ of underweight than those living in urban areas (18.6\%). Indicates that children living in rural areas have a higher level of starvation than those living in urban areas. As a result, a child's residency has a significant effect on the prevalence of underweight with chi square value 216.79 ( $p=0.001)$. Muslims have shown highest prevalence underweight with 36.5 percent, led by Hindus (23.6\%). Also, the sex of the household head and household members does not show any significant impact on the prevalence of underweight as the chi square value is very low and insignificant. The prevalence is lowest amongst the children belonging to the richest family $(13.2 \%)$ and highest among poorer wealth quantile with 37.2 percent, hence there is a very strong and negative association between the wealth index of the household and underweight prevalence ( $\nabla^{2}$ value 1038.92, $p=0.001$ ). Schedule Caste has the lowest prevalence of underweight (25.5\%). Similarly, children that do not have improved toilet facilities or clean drinking water have higher prevalence of underweight than those who do, indicating that sanitation and cleanliness plays a substantial role in a child's underweight status. Before applying the multivariable regression 
analysis, we check the collinearity of all predictor variables with variance inflation factor and result shows less than 5.7, and it could be considered that there was no multicollinearity, and therefore, all predictor variables were included in the binary logistic regression model.

Column 3 and 4 depicts binary logistic regression (crude and adjusted, respectively) for underweight among children under five years of age in the Northeast States, India (2015-16). It shows the crude and adjusted odds ratios for the association between underweight by various background characteristics.

Children whose mother's level of education was no education and primary were $1.30(p=0.001)$ times and $1.74(p=0.001)$ times more likely to be underweight than those whose mother's level of education was secondary or above. Children with small size at birth have a $1.32(p=0.001)$ times higher risk of being underweight as compared to those having size average and above size at birth. Male children were having a $0.13(p=0.001)$ times lower risk of being underweight as compared its counterpart. The risk of being underweight was $1.71(p=0.001), 2.01(p=0.01), 2.01(p=0.001)$, and $2.24(p=0.001)$ times higher in the ages $1,2,3,4$ respectively as compared to those at the age 0 . Children who were ever breastfed and then stopped were at $0.11(p=0.05)$ times less risk of becoming underweight as compared to those who were never breastfed. Muslims had $1.31(p=0.001)$ times, and Christians had $1.19(p=0.05)$ times higher risk of being underweight as compared to Hindus. Children belonging to poorest had $2.12(p=0.001)$, poorer had $1.87(p=0.001)$, middle had $1.89(p=0.001)$, richer had $1.57(p=0.001)$ times higher risk of being underweight as compared to children belonging to the richest wealth index. Scheduled Tribes had a $0.42(p=0.001)$ times lesser risk of being underweight as compared to that of others. Households with unimproved toilet facilities had $1.11(p=0.01)$ times higher risk of being underweight than those with improved one.

\section{Odds Ratio Graphs}

Table 2 shows the results of multilevel analysis of the variables related to underweight among children under five years of age in Northeast states, India, NFHS-4 (2015-16). Underweight risk was 0.07 ( $p=0.05)$ times lesser for children whose mothers were in the age group 25-34 years relative to those whose mothers were in the age group 15-24 years. Children whose mother's level of education was no education or primary were $1.13(p=0.01)$ times and $1.34(p=0.001)$ times more likely to be underweight respectively than those whose mother's level of education was secondary and above. As compared to children who are average or above in size at birth, those who are small in size at birth have a $1.41(p=0.001)$ times higher chance of being underweight. Female children were having $1.15(p=0.001)$ times higher risk of underweight as compared to that of male children. The risk of being underweight was $1.77(p=0.001)$, $2.17(p=0.01), 2.28(p=0.001)$, and $2.44(p=0.001)$ times higher in the ages of $1,2,3$, and 4 respectively as compared to those in the age 0 . Hence, as age increases risk of being underweight increases up-to age five which means, age 1-5 are crucial years of life. Children with a birth order two and interval one had a $1.29(p=0.001)$ times greater chance of being underweight as compared to those with a birth order of one. Muslims had $1.36(p=0.001)$, Christians had $1.15(p=0.05)$ times higher risk of being underweight as compared to those of Hindus. Children in the richer wealth quintile had $1.58(p=0.001)$, middle wealth 
quantile had $1.89(p=0.001)$, poorer wealth index children had $2.05(p=0.001)$, and poorest had 2.45 $(p=0.001)$ times higher chance of being underweight as compared to that of the richest wealth quintile. Schedule Tribe had $0.40(p=0.001)$ times lower risk of being underweight as compared to that of others. Those children with no safe cooking fuel had in their household had shown a $1.12(p=0.05)$ times higher risk of being underweight than those with safe cooking fuel.

Present study shows that in northeastern states the risk of underweight is the lowest among Schedule Tribes with the lowest prevalence and risk as compared to its counterparts whereas in India, the overall prevalence of underweight is highest among STs unlike the results shown in some studies already being done (Usmani G, 2017). In present study, the prevalence and risk of becoming underweight was lower among boys than in girls, like in another study, underweight was found to be more common in girls because they were fed less than boys (Chen, 1981). Study also suggests that age 1-5 years are crucial age and hence need and extra care.

Table 3 depicts the risk difference between underweight of children under five years of age belonging to poor and non-poor household in the northeast, India (2015-16). Three of the eight states studied, Assam, Arunachal Pradesh, and Meghalaya, have shown higher risk differences. In Assam, children from poor households, on average, are underweight 11.1 percentage points more often than those of non-poor households. Similarly, in Arunachal Pradesh and Meghalaya, those belonging to poor household are 9.3 percentage and 8.3 percentage points more often to be underweight, respectively than those to a nonpoor household.

\section{Conclusion}

The relationships between underweight and socio-cultural and demographic influences that could explain variance in underweight among children in India's northeast states were examined in this research.

In general, the whole study shows that girls are highly vulnerable to underweight as compared to boys of the same age group, i.e., under the age of five years in northeast India. Present study suggests that education of mother plays a very substantial role in child's underweight status in early ages. Along with child's sex, age and other individual factors, some social factors such as type of residence, social status, and household's wealth index can also greatly affect the underweight among children. Muslims had shown highest vulnerability of underweight among infants compared to other communities.

To combat the problem of underweight among children in India's northeast states, policymakers must be more thoughtful and make policies with a strong reliance on communities with a higher prevalence and risk of underweight. For example, by promoting awareness and informing parents about the various causes that lead to their child's underweight and the consequences of this condition. Furthermore, some measures of underweight in northeastern states by different categories were entirely contrary to those obtained at the national level, suggesting that northeastern states need special consideration. 


\section{Limitations And Strengths Of The Study}

The present study's power stems from the fact that finding of the study can be generalized to all the districts across the northeastern states of India and may help identify appropriate population goals. It considers the hierarchical level of the data to overcome any variation caused by the hierarchical structure. While this analysis has many strengths, it also has certain shortcomings in terms of evaluating the data. Firstly, it does not consider the mother's dietary status, which may help to understand whether children are underweight. As a result, future research can further integrate the above and determine a much more rational significant link between underweight status and different factors at mother's level. Secondly, infant immunizations may have an indirect effect on childhood underweight status, but they were not included in this study. Another limitation of the study is that the findings of the study cannot be generalized to all the districts across all the states of India. These weaknesses can be addressed in future studies by taking a systematic approach.

\section{Declarations}

\section{Ethics Statement}

Present study is based on a secondary data set from the recent NFHS-4 survey with no identifiable information on the survey participants. This dataset is available in the public domain for various research purposes. Hence, no ethical approval was needed.

\section{Consent for Publication}

Not applicable

\section{Availability of Data and Material}

The data can be freely accessed from the website at https://www.dhsprogram.com/data/availabledatasets.cfm.

\section{Competing Interest}

The authors declare that they have no known competing financial interests or personal relationships that could have appeared to influence the work reported in this paper.

\section{Funding}

This research did not receive any specific grant from funding agencies in the public, commercial, or notfor-profit sectors.

\section{Author's Contributions}


KC, JKS conceived the idea for the study and developed the analysis plan. KC, JKS, VC led the analysis. $\mathrm{KC}$, JKS, DM organized the first draft of manuscript. KC, $\mathrm{DM}$, and $\mathrm{VC}$ led the interpretation of the results. $\mathrm{KC}$ and $\mathrm{DM}$ did the manuscript writing. All authors read and approved the final manuscript.

\section{Acknowledgment}

We would like to acknowledge M. Vishnu Vardhana Rao who facilitated the authors for carrying out the research work. We are grateful to the Indian Council of Medical Research for their assistance (ICMR). This study was carried out as part of an ICMR short-term studentship in 2018.

\section{References}


1. Belitz, C., Hübner, J., Klasen, S., \& Lang, S. (2010). Determinants of the socioeconomic and spatial pattern of undernutrition by sex in India: A geoadditive semi-parametric regression approach. In Statistical modelling and regression structures (pp. 155-179). Physica-Verlag HD.

2. Bhutia, D. T. (2014). Protein energy malnutrition in India: the plight of our under five children. Journal of Family Medicine and Primary Care, 3(1), 63.

3. Black, R. E., Allen, L. H., Bhutta, Z. A., Caulfi, L. E., Onis, M. D., Ezzati, M., \& Rivera, J. (2008). Maternal and Child Undernutrition 1 Maternal and child undernutrition: global and regional, 243-260.

4. Chen, L. C., Huq, E., \& d'Souza, S. (1981). Sex bias in the family allocation of food and health care in rural Bangladesh. Population and development review, 55-70.

5. Chyne, D. A. L., Meshram, I. I., Rajendran, A., Kodali, V., Getti, N., Roy, P., ... \& Longvah, T. (2017). Nutritional status, food insecurity, and biodiversity among the $\mathrm{K}$ hasi in $\mathrm{M}$ eghalaya, $\mathrm{N}$ orth-East I ndia. Maternal \& Child Nutrition, 13, e12557.

6. Dandona, R., Kumar, G. A., Henry, N. J., Joshua, V., Ramji, S., Gupta, S. S., ... \& Dandona, L. (2020). Subnational mapping of under-5 and neonatal mortality trends in India: The Global Burden of Disease Study 2000-17. The Lancet, 395(10237), 1640-1658.

7. Dinachandra Singh, K., Alagarajan, M., \& Ladusingh, L. (2015). What explains child malnutrition of indigenous people of Northeast India?. PLoS One, 10(6), e0130567.

8. Gragnolati, M., Shekar, M., Das Gupta, M., Bredenkamp, C., \& Lee, Y. K. (2005). India's undernourished children: a call for reform and action.

9. International Institute for Population Sciences (IIPS) and ICF. 2017. National Family Health Survey (NFHS-4), 2015-16: India. Mumbai: IIPS.

10. Indian Institute for Population Sciences (IIPS) and MoHFW. National Family Health Survey -4 . 2017. Available from: https://www.dhsprogram.com/data/available-datasets.cfm.

11. Ministry of Women and Child Development. (2015). Rapid Survey on Children 2013-2014.

12. Rabbi, A. M. F., \& Karmaker, S. C. (2015). Determinants of child malnutrition in Bangladesh-A multivariate approach. Asian journal of medical sciences, 6(2), 85-90.

13. Roy, A., Singh, N. U., Dkhar, D. S., Mohanty, A. K., Singh, S. B., \& Tripathi, A. K. (2015). Food security in north-east region of India-A state-wise analysis. Agricultural Economics Research Review, 28(347-2016-17191), 259-266.

14. Swaminathan, S., Hemalatha, R., Pandey, A., Kassebaum, N. J., Laxmaiah, A., Longvah, T., ... \& Dandona, L. (2019). The burden of child and maternal malnutrition and trends in its indicators in the states of India: the Global Burden of Disease Study 1990-2017. The Lancet Child \& Adolescent Health, 3(12), 855-870.

15. Tom A. B. Snijders, (2012). Multilevel Analysis. Department of Statistics, University of Oxford

16. Von Grebmer, K., Bernstein, J., Brown, T., Prasai, N., Yohannes, Y., Towey, O., \& Hossain, N. (2017). Global Hunger Index 2017: The Inequalities of Hunger.

17. Wang, Y., Chen, H. J., Shaikh, S., \& Mathur, P. (2009). Is obesity becoming a public health problem in India? Examine the shift from under-to overnutrition problems over time. Obesity Reviews, 10(4), 456-474.

18. WHO, 2020. Malnutrition Fact Sheet. World Health Organization, Geneva. 
19. World Health Organization. (2020). UNICEF/WHO/The World Bank Group joint child malnutrition estimates: levels and trends in child malnutrition: key findings of the 2020 edition.

\section{Appendix}


Table-1: Percent distribution, underweight prevalence, Crude, and Adjusted Odds Ratio of children under five years of age by background characteristics in Northeast state, India, NFHS-4 (2015-16)

$\begin{array}{llll}\begin{array}{l}\text { Percentage } \\ \text { (Sample) }\end{array} & \text { Underweight } & \begin{array}{l}\text { Crude } \\ \text { OR }\end{array} & \text { Adjusted OR [LL- } \\ (n=32005) & & \end{array}$

Age group

\begin{tabular}{lllll}
$15-24 \mathrm{yr}$ & $33.1(8,613)$ & 27.7 & - & - \\
\hline $24-34 \mathrm{yr}$ & $53.0(17,784)$ & 26.5 & 0.94 & $0.91[0.82,1.01]$ \\
\hline $35-49 \mathrm{yr}$ & $13.9(5,608)$ & 29.9 & 1.11 & $0.93[0.79,1.09]$ \\
$\square^{2}$ value & & $21.27^{\star}$ & &
\end{tabular}

Level of Education

\begin{tabular}{|c|c|c|c|c|}
\hline No Education & $21.1(6,073)$ & 41.4 & 1.73 & $\begin{array}{l}1.30 * \star \star \\
{[1.17,1.47]}\end{array}$ \\
\hline Primary & $17.1(5,714)$ & 31.9 & 2.61 & $\begin{array}{l}1.74 \star \star \star \\
{[1.55,1.95]}\end{array}$ \\
\hline Secondary and above & $61.2(20,218)$ & 21.2 & - & - \\
\hline$\square^{2}$ value & & \multicolumn{2}{|c|}{$1093.2953^{\star \star *}$} & \\
\hline \multicolumn{5}{|l|}{ Size of child } \\
\hline Average and above & $79.5(26,298)$ & 28.6 & - & - \\
\hline Small & $20.5(5,707)$ & 26.1 & 1.56 & $\begin{array}{l}1.32 \star \star \star \\
{[1.19,1.47]}\end{array}$ \\
\hline$\square^{2}$ value & & \multicolumn{2}{|c|}{$24.1352^{\star \star \star}$} & \\
\hline \multicolumn{5}{|l|}{ Sex of child } \\
\hline Male & $51.5(16,300)$ & 28.6 & - & - \\
\hline Female & $48.5(15,705)$ & 26.1 & 0.88 & $0.87^{\star \star}[0.79,0.95]$ \\
\hline$\square^{2}$ value & & \multicolumn{2}{|c|}{$24.1352^{\star \star}$} & \\
\hline \multicolumn{5}{|l|}{ Age of child } \\
\hline 0 & $17.7(5,583)$ & 18.2 & - & - \\
\hline 1 & $20.3(6,505)$ & 26.5 & 1.62 & 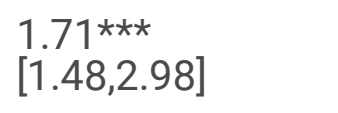 \\
\hline 2 & $20.5(6,550)$ & 29.7 & 1.89 & $\begin{array}{l}2.01 * \star \star \\
{[1.73,2.32]}\end{array}$ \\
\hline
\end{tabular}




\begin{tabular}{|c|c|c|c|c|}
\hline 3 & $21.6(6,861)$ & 29.5 & 1.88 & $\begin{array}{l}2.01 \star \star \star \\
{[1.73,2.33]}\end{array}$ \\
\hline 4 & $19.9(6,506)$ & 31.7 & 2.09 & $\begin{array}{l}2.24 \star \star \star \\
{[1.91,2.62]}\end{array}$ \\
\hline$\square^{2}$ value & & 336.2021 *** & & \\
\hline \multicolumn{5}{|l|}{$\begin{array}{l}\text { Birth Order and interval of } \\
\text { child }\end{array}$} \\
\hline Birth order 1 & $68.9(20,417)$ & 24.7 & - & - \\
\hline $\begin{array}{l}\text { Birth order } 1 \& \text { birth interval } \\
1\end{array}$ & $2.8(1,128)$ & 36.5 & 1.31 & $1.31[1.04,1.66]$ \\
\hline $\begin{array}{l}\text { Birth order } 1 \& \text { birth interval } \\
2\end{array}$ & $12.3(4,072)$ & 30.5 & 1.08 & $1.08[1.04,1.24]$ \\
\hline $\begin{array}{l}\text { Birth order } 2 \text { \& birth interval } \\
1\end{array}$ & $3.6(1,588)$ & 36.4 & 1.74 & $1.21[0.98,1.51]$ \\
\hline $\begin{array}{l}\text { Birth order } 2 \& \text { birth interval } \\
2\end{array}$ & $12.3(4,800)$ & 3.6 & 1.61 & $1.11[0.96,1.29]$ \\
\hline$\square^{2}$ value & & $288.4994^{\star \star \star}$ & & \\
\hline \multicolumn{5}{|l|}{ Duration of Breastfeeding } \\
\hline Never & $10.5(2,582)$ & 29.5 & - & - \\
\hline Stopped breastfeeding & $18.4(7,379)$ & 26.7 & 0.97 & $0.89[0.79,0.99]$ \\
\hline Still breastfeeding & $71.1(22,044)$ & 27.3 & 1.12 & $0.87[0.75,1.02]$ \\
\hline$\square^{2}$ value & & $9.1993^{\star \star \star}$ & & \\
\hline \multicolumn{5}{|l|}{ Religion } \\
\hline Hindu & $46.9(9,727)$ & 23.6 & - & - \\
\hline Muslim & $32.1(4,494)$ & 36.3 & 1.86 & $\begin{array}{l}1.31 * \star \star \\
{[1.13,1.51]}\end{array}$ \\
\hline Christian & $18.1(15,227)$ & 21.9 & 0.91 & $1.19 *[1.02,1.39]$ \\
\hline Others & $2.9(2,557)$ & 21.6 & 0.89 & $1.00[0.80,1.26]$ \\
\hline$\square^{2}$ value & & $644.9041^{\star \star \star}$ & & \\
\hline \multicolumn{5}{|l|}{ Sex of Household head } \\
\hline Male & $88.7(28,224)$ & 27.5 & - & - \\
\hline Female & $11.3(3,781)$ & 26.4 & 0.95 & $1.10[0.96-1.26]$ \\
\hline$\square^{2}$ value & & 1.9046 & & \\
\hline
\end{tabular}




\begin{tabular}{|c|c|c|c|c|}
\hline \multicolumn{5}{|l|}{ Household members } \\
\hline 4 or less & $32.1(10,006)$ & 26.3 & - & - \\
\hline $5-8$ & $56.0(18,426)$ & 28.5 & 1.12 & $1.05[0.95-1.16]$ \\
\hline 9 or more & $11.9(3,576)$ & 25.0 & 0.93 & $1.01[0.87-1.18]$ \\
\hline$\square^{2}$ value & & $29.6736 \star \star$ & & \\
\hline \multicolumn{5}{|l|}{ Wealth index quintile } \\
\hline Richest & $15.1(4,145)$ & 13.2 & - & - \\
\hline Richer & $18.7(5,675)$ & 21.4 & 1.79 & $\begin{array}{l}1.54 \star \star \star \\
{[1.24,1.90]}\end{array}$ \\
\hline Middle & $19.8(6,365)$ & 27.4 & 2.48 & $\begin{array}{l}1.82 \star * \star \\
{[1.46,2.27]}\end{array}$ \\
\hline Poorer & $21.2(6,152)$ & 31.1 & 2.97 & $\begin{array}{l}1.87 \star \star \star \\
{[1.48,2.36]}\end{array}$ \\
\hline Poorest & $25.3(8,668)$ & 37.2 & 3.91 & $\begin{array}{l}2.12 * \star * \\
{[1.67,2.71]}\end{array}$ \\
\hline$\square^{2}$ value & & $1038.9187 * \star \star$ & & \\
\hline \multicolumn{5}{|l|}{ Social status } \\
\hline Schedule Caste & $8.6(1,864)$ & 25.5 & 0.71 & $0.96[0.87,1.19]$ \\
\hline Schedule Tribe & $28.7(18,815)$ & 26.5 & 0.53 & $\begin{array}{l}0.58 * \star \star \\
{[0.49,0.68]}\end{array}$ \\
\hline Other Backward Classes & $18.6(3,518)$ & 26.7 & 0.71 & $1.05[0.87,1.19]$ \\
\hline Others & $44.0(7,808)$ & 30.3 & - & - \\
\hline$\square^{2}$ value & & $46.0451 * \star \star$ & & \\
\hline \multicolumn{5}{|l|}{ Toilet facilities } \\
\hline Improved & $61.3(23,055)$ & 23.1 & - & - \\
\hline Not improved & $38.7(8,950)$ & 34.2 & 1.72 & 1.11 ** $[1.01,1.23]$ \\
\hline$\square^{2}$ value & & $468.4575^{\star \star \star}$ & & \\
\hline \multicolumn{5}{|l|}{ Safe drinking facility } \\
\hline Yes & $78.8(23,680)$ & 27.6 & - & - \\
\hline No & $21.2(8,325)$ & 26.6 & 0.95 & $0.92[0.99-1.03]$ \\
\hline$\square^{2}$ value & & 2.6961 & & \\
\hline
\end{tabular}




\begin{tabular}{|lllll|}
\hline Safe cooking fuel & & & \\
\hline Yes & $21.2(8,911)$ & 16.1 & - & - \\
\hline No & $78.8(23,094)$ & 30.4 & 2.28 & 1.16 [0.99-1.37] \\
\hline$\square^{2}$ value & & $551.6699 * \star *$ & & \\
\hline Place of Residence & & & \\
\hline Urban & $14.9(9,840)$ & 18.6 & - & - \\
\hline Rural & $85.1(25,165)$ & 28.9 & 1.78 & $1.00[0.86,1.16]$ \\
\hline$\square^{2}$ value & & $216.7852^{\star \star *}$ & & \\
\hline Total & & 27.4 & & \\
\hline
\end{tabular}

Table 1 * significant at $5 \%$ level of significance, ${ }^{\star \star}$ significant at $1 \%$ level of significance, and $* \star \star$ significant at $0.1 \%$ level of significance. 
Table-2: Results of multilevel analysis of the variables related to underweight among children under five years in Northeast states, India, NFHS-4 (2015-16)

Adjusted OR $\quad 95 \% \mathrm{Cl}$ p value

Age group

$15-24 \mathrm{yr} \circledast$

25-34yr

$0.93^{*}$

$[0.86,1.0]$

0.050

$35-49 \mathrm{yr}$

0.95

$[0.86,1.04]$

0.266

Level of Education

No Education

$1.13^{\star *}$

[1.04,1.22]

0.004

Primary

$1.34^{\star \star \star}$

$[1.23,1.46]$

0.000

Secondary and above ${ }^{\circledR}$

Size of child

Average and above ${ }^{\circledR}$

Small

$1.41^{\star \star \star}$

[1.31,1.52]

0.000

Sex of child

Male $\AA$

Female

$1.15^{\star \star \star}$

$[1.09,1.22]$

0.000

Age of child

$$
0 \AA
$$

1

$1.77^{\star \star \star}$

$[1.59,1.97]$

0.000

2

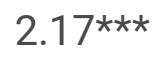

[1.95,2.41]

0.000

3

$2.28^{\star \star \star}$

[2.04,2.53]

0.000

4

$2.44^{\star \star \star}$

$[2.18,2.71]$

0.000

Birth Order of child

Birth order $1 \AA$

Birth order 1 \& interval 1

1.19*

$[1.03,1.40]$

0.022

Birth order 1 \& interval 2

1.07

$[0.97,1.18]$

0.140

Birth order 2 \& interval 1

$1.29 \star * \star$

[1.12,1.47]

0.000

Birth order 2 \& interval 2

1.02

$[0.92,1.11]$

0.731

Duration of Breastfeeding 


\begin{tabular}{|c|c|c|c|}
\hline Never ${ }^{\circledR}$ & - & - & - \\
\hline Stopped breastfeeding & $0.92^{\star}$ & {$[0.85,0.99]$} & 0.035 \\
\hline Still breastfeeding & 0.92 & {$[0.82,1.03]$} & 0.147 \\
\hline \multicolumn{4}{|l|}{ Religion } \\
\hline Hindu ${ }^{\circledR}$ & - & - & - \\
\hline Muslim & 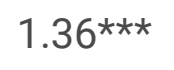 & {$[1.19,1.54]$} & 0.000 \\
\hline Christian & $1.15^{\star}$ & {$[1.00,1.32]$} & 0.045 \\
\hline Others & 0.95 & {$[0.82,1.12]$} & 0.562 \\
\hline \multicolumn{4}{|l|}{ Sex head household } \\
\hline Male ${ }^{\circledR}$ & - & - & - \\
\hline Female & 1.01 & {$[0.92,1.11]$} & 0.812 \\
\hline \multicolumn{4}{|l|}{ Household members } \\
\hline 4 or less member ${ }^{\circledR}$ & - & - & - \\
\hline 5-8 members & 1.07 & {$[0.99,1.15]$} & 0.089 \\
\hline 9 or more members & 1.02 & {$[0.91,1.14]$} & 0.720 \\
\hline \multicolumn{4}{|l|}{ Wealth index quintile } \\
\hline Richest ${ }^{\circledR}$ & - & - & - \\
\hline Richer & $1.58^{\star \star \star}$ & {$[1.38,1.82]$} & 0.000 \\
\hline Middle & $1.89 * \star \star$ & {$[1.63,2.18]$} & 0.000 \\
\hline Poorer & $2.05^{\star \star \star}$ & {$[1.76,2.39]$} & 0.000 \\
\hline Poorest & $2.45^{\star \star \star}$ & {$[2.08,2.89]$} & 0.000 \\
\hline \multicolumn{4}{|l|}{ Social status } \\
\hline Schedule Caste & 0.98 & {$[0.87,1.11]$} & 0.801 \\
\hline Schedule Tribe & $0.60 * \star \star$ & {$[0.52,0.69]$} & 0.000 \\
\hline Other Backward Classes & 0.92 & {$[0.79,1.07]$} & 0.267 \\
\hline Others ® & - & - & - \\
\hline \multicolumn{4}{|l|}{ Toilet facilities } \\
\hline Improved ${ }^{\circledR}$ & - & - & - \\
\hline Not improved & 1.07 & {$[0.99,1.16]$} & 0.065 \\
\hline
\end{tabular}

Page 18/21 
Yes ${ }^{\circledR}$

No

Safe drinking Facilities

Yes ${ }^{\circledR}$

No

Place of Residence

Urban ${ }^{\circledR}$

Rural

0.99

$[0.89,1.10]$

0.826

Table 2 * significant at $5 \%$ level of significance, ${ }^{* \star}$ significant at $1 \%$ level of significance, and ${ }^{* \star}$ significant at $0.1 \%$ level of significance. $\circledast$ Reference category.

\section{Table-3: Risk Difference for Underweight among children under five years in Northeast states, India,} NFHS-4 (2015-16)

\begin{tabular}{|lllll|}
\multicolumn{2}{l}{ Underweight } & \multicolumn{2}{l|}{$\begin{array}{l}\text { Underweight risk difference } \\
p \text { value }\end{array}$} \\
\hline States & Poor\% & Non-Poor\% & Crude risk difference & Adjusted Risk Difference \\
\hline Arunachal Pradesh & 22.10 & 11.72 & $15.1[11.7,18.4]$ & $9.3[6.7,11.9]$ \\
\hline Assam & 34.06 & 17.93 & $17.5[15.5,19.5]$ & $11.1[8.9,13.2]$ \\
\hline Manipur & 16.09 & 10.57 & $10[6.7,13.4]$ & $4.8[2.8,6.9]$ \\
\hline Meghalaya & 32.45 & 22.91 & $8.7[5.8,11.9]$ & $8.3[5,11.6]$ \\
\hline Mizoram & 15.92 & 7.39 & $13.2[10.2,16.3]$ & $6.8[4.5,9.1]$ \\
\hline Nagaland & 19.19 & 11.26 & $10.8[7.5,14]$ & $7.1[4.5,9.8]$ \\
\hline Sikkim & 16.59 & 11.07 & $8.7[11.8,16.3]$ & $3.7[-1.6,9]$ \\
\hline Tripura & 28.83 & 18.98 & $11.7[5.9,17.6]$ & $7.8[2.2,13.3]$ \\
\hline
\end{tabular}

Table 3: Risk Difference for Underweight

\section{Figures}


child underweight coded: $0=$ No, $1=$ Yes

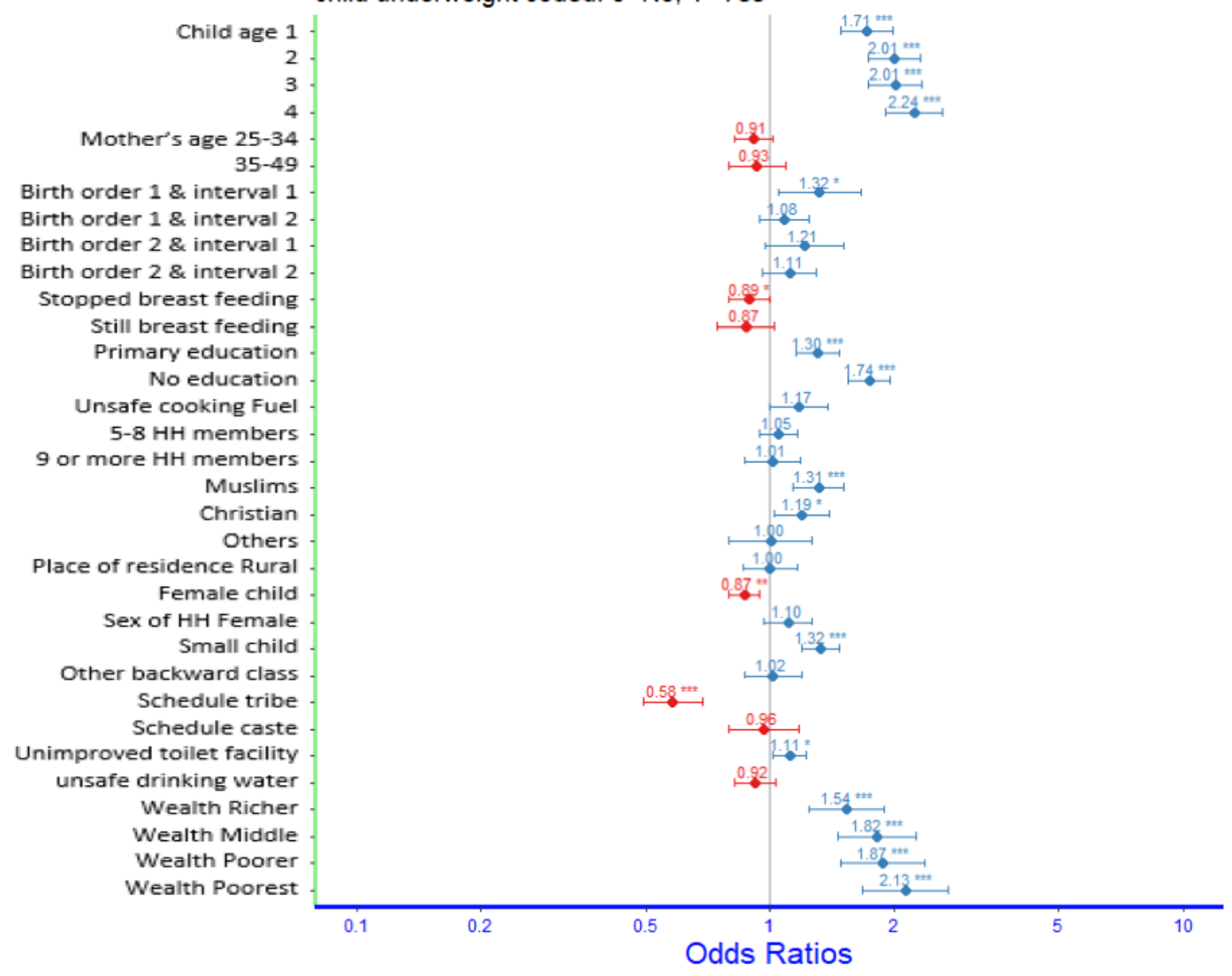

\section{Figure 1}

Figure a. Odds Ratio graph for underweight. among children under 5 years in North-eastern States, India (2015-16) 


\section{Risk Difference for underweight}

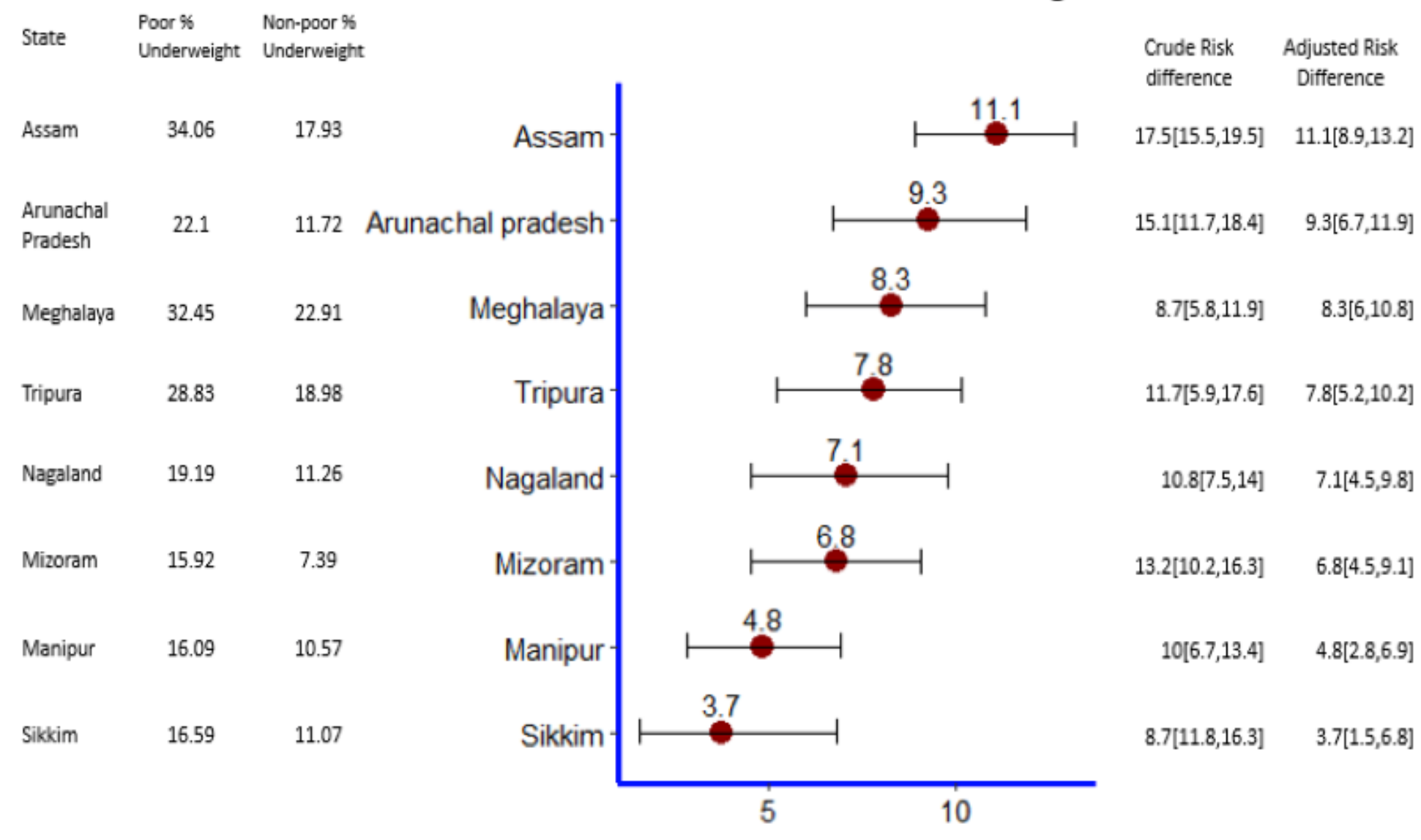

Figure 2

Figure b. Risk difference graph for underweight among children under 5 years in North-eastern States, India (2015-16) 